\title{
To Evert or not to Evert Tunica Vaginalis during Low Inguinal Approach Varicocelectomy
}

\author{
Shawky Mohammed Deabes, Mohamed Abdel-all Nafea, Ahmed Soliman Ibrahim* \\ Department of General Surgery, Faculty of Medicine, Al-Azhar University, Cairo, Egypt \\ *Correspondence author: ahmed soliman Ibrahim ahmed, Mobile: (+20) 01227993674,
}

E-mail: ahmed.sol.ib.88@gmail.com

\section{ABSTRACT}

Background: Varicocele is the most common correctable etiology found in infertile men. The aim of all surgical methods that treating varicocele is to increase the potential for future fertility.

Objective: The aim of work was to evaluate the outcome of varicocelectomy through the low inguinal approach as a compare of eversion or non-eversion of the tunica vaginalis.

Patients and methods: This prospective study included a total of 40 patients with a diagnosis of primary testicular varicocele and underwent low approach varicocelectomy, attending at Department of General Surgery, El-Hussein University Hospital. The patients were divided into two groups: group I included 20 patients with everted tunica and group II included 20 patients without everted tunica.

Results: show that eversion of tunica vaginalis proved statistically to be effective in avoidance of hydrocele formation after varicocelectomy as there is no case developed hydrocele during the follow up period and as effective as microsurgical varicocelectomy. Conclusion: It could be concluded that for reduction of the incidence of hydrocele after varicocelectomy, eversion of tunica vaginalis can be afforded as adjunctive in operation theatre performing sub inguinal varicocelectomy without the aid of an operating microscope.

Keywords: varicocelectomy, hydrocele.

\section{INTRODUCTION}

Primary varicocele is the most common prepubertal andrological condition. it has first been described as early as 1st century B.C. Armelius Cornelius Celsus wrote "when the disease has spread over the testicle and its cord, the testicle sinks a little lower, and becomes smaller than its fellow, in as much as its nutrition has become defective" ${ }^{(I)}$.

Early description of varicocele in the modern literature was in 1885 when a conventional description of surgical treatment was given by Barwell (2).

However, it has only been in the last two decades those adolescent varicoceles have been proven to affect the growth and function of the testis ${ }^{(3)}$.

Varicocele in pediatric and adolescent was thought to be clinically ineffective as early as 1970s. This belief then changed when Kogan et al. ${ }^{(4)}$.

Some clinical studies confirmed that there was a reduction in ipsilateral testicular volume of the varicocele, which leads to change of the way of treatment of varicocele. It is now proven that there is an increase in both ipsilateral and contralateral testicular growth in children and adolescents who have undergone varicocele treatment compared with those who had not ${ }^{(4)}$.

Varicocele is the most common correctable etiology found in infertile men. The aim of all surgical methods that treating varicocele is to increase the potential for future fertility ${ }^{(5)}$.

The main goal of treatment in children is to prevent testicular injury and maintain testicular normal function, which can be achieved by surgical treatment of varicoceles ${ }^{(4)}$.

The ideal surgical treatment for varicocele would be one where the varicocele is completely eliminated, while testicular function is preserved with a low rate of recurrence, hydrocele formation, no nerve damage or any other potential complications ${ }^{(6)}$.

Despite the well-established natural history of the varicocele disease process, the optimal method for ligation of the varicocele is still a matter of debate as more interventional radiology as well as minimal invasive surgical procedures is ever emerging ${ }^{(7)}$.

The aim of the study was to evaluate the outcome of varicocelectomy through the low inguinal approach as a compare between eversion and non-eversion of the tunica vaginalis.

\section{PATIENTS AND METHODS}

This prospective study included a total of 40 patients with a diagnosis of primary testicular varicocele and underwent low approach varicocelectomy, attending at Department of General Surgery, El-Hussein University Hospital. Written informed consent from all the subjects were obtained after complete explanation of the procedure and any possible complications they may suffer. This study was conducted between December 2018 to June 2019.

\section{Ethical approval:}

The study was approved by the Ethics Board of AlAzhar University and an informed written consent was taken from each participant in the study.

The included subjects were randomly divided into two groups; Group I (with eversion of tunica) consisted of 20 patients whose ages ranged from 17 to 52 years, with a mean age of $30.75 \pm 10.67$ years, and who underwent varicocelectomy with eversion of tunica, Group II (with non-everted tunica) consisted of 20 patients, with ages ranging from 16 to 48 years and a mean age of $29.35 \pm 8.93$ years, who underwent low approach varicocelectomy only. 
Diagnosis of varicoceles was done by scrotal examination while the patient in a standing position and during Valsalva's maneuver. Varicoceles were classified as grade I (palpable only during Valsalva's maneuver), grade II (palpable without Valsalva's maneuver), and grade III (visible). The Diagnosis was confirmed by scrotal color Doppler ultrasound and testicular volume was assessed. Semen analysis was done for all patients according to WHO 2010.

\section{Basic laboratory investigations including}

(CBC, liver function tests, urea, creatinine, prothrombin time, and fasting plasma glucose) were done for all patients before operation to exclude ineligible case.

Inclusion criteria: patients having unilateral or bilateral (idiopathic) primary varicocele.

Exclusion criteria: all patients clinically or by ultrasound findings suspected to have testicular tumor, blood clotting problem, hypoalbuminemia, generalized anasarca or previous hydrocelectomy.

\section{Surgical Technique of varicocele Operation (low inguinal approach)}

\section{Preoperative Patient Preparation:}

All patients were positioned in supine position before General, spinal or local anesthesia. Perioperative antibiotic injected as a prophylaxis to avoid the risk factors for wound infection. Complete shaving and washing of the scrotum and inguinal region followed by povidone iodide (Betadine ${ }^{\mathrm{TM}}$ ) disinfection.

Antibiotic prophylaxis and Anesthesia: third generation of caephalosporin $1 \mathrm{~g}$ IV preoperative was given. Operation was done under spinal anesthesia.

\section{Surgical Approach for Varicocelectomy:}

Group I: inguinal approach with eversion of tunica vaginalis: Scrotal exposure was necessarily followed by inguinal incision at the level of external ring then open scarps fascia and delivery of the cord was done. Open the cord through cremasteric fascia then start to ligate and cut all pampiniform plexus and cremasteric veins with preservation of the artery and lymphatic vessels. Delivery of the testis through the incision and open tunica vaginalis then evert it. Back the testis and the cord to its position with good hemostasis. Closure of the skin and subcutaneous fascia was done with drain insertion.

Operative notes recorded including, intraoperative complications, operative time, postoperative complications and amount of daily drain output and time of drain removal in each group. A comparison made between the two groups as regard; operative time, postoperative hematoma, seroma formation and wound sepsis, length of hospital stay and time of return to daily life. Data collection sheets filled in by the surgeon himself, these sheets included; each patient age, height and weight, any earlier surgical or medical problems, clinical pathology investigations, operative time, postoperative hematoma, Seroma formation, wound sepsis, length of hospital stay, time of return to daily life, time of drain removal in group I, follow-ups (after 2 weeks, 1 month, 2 months and 3 months intervals), formation of hydrocele, and recurrence of varicocele.

Group II: Inguinal approach without eversion of tunica vaginalis: In each operated patient, scrotal exposure was necessary then mark incision site in the inguinal area just at the level of external inguinal ring, followed by incision of the skin and scarps fascia by electrocautery then delivery of the cord is done and fix the cord outside to operate easily then open the cord through open in cremasteric fascia by electrocautery identification of the vas deference to avoid its injury and veins of pampiniform plexus, isolation of the vein to avoid injury of any structure,crush two ended vein, and cut between them, ligate each end with vicryle $0 \backslash 3$ search for other veins and ligate them with the same manner identification of cremasteric vein and ligate it with the same manner. Make sure no other veins are found then put the cord back after good hemostasis and close fascia and skin in two layers with no drain insertion.

\section{Statistical Analysis}

Data were collected, revised, coded and entered to the Statistical Package for Social Science (IBM SPSS) version 23. The qualitative variables were presented as number and percentages.

The comparison between groups regarding qualitative data was done by using Chi-square test.

The confidence interval was set to $95 \%$ and the margin of error accepted was set to 5\%. So, the p-value was considered significant as the following: $\mathrm{P}$-value $>$ 0.05: Nonsignificant (NS). P-value < 0.05: Significant (S). P-value < 0.01: Highly significant (HS).

\section{RESULTS}

Table (1): Comparison between group I and group II regarding age of the studied cases.

\begin{tabular}{|l|c|c|c|c|c|c|c|}
\hline \multirow{2}{*}{ Age } & \multicolumn{2}{|c|}{ Group I } & \multicolumn{2}{c|}{ Group II } & \multirow{2}{*}{ Test value* } & \multirow{2}{*}{ P-value } & \multirow{2}{*}{ Sig. } \\
\cline { 2 - 8 } & No. & \% & No. & \% & & & \\
\hline 17-30 years & 6 & $30.0 \%$ & 5 & $25.0 \%$ & & & \\
31-40 years & 8 & $40.0 \%$ & 9 & $45.0 \%$ & 0.150 & 0.927 & NS \\
41-52 years & 6 & $30.0 \%$ & 6 & $30.0 \%$ & & & \\
\hline
\end{tabular}


The previous table shows that there was no statistically significant difference found between group I and group II regarding age of the studied cases with $\mathrm{p}$-value $=0.927$.

Table (2): Comparison between group I and group II regarding affected side.

\begin{tabular}{|l|c|c|c|c|c|c|c|}
\hline \multirow{2}{*}{ Side } & \multicolumn{2}{|c|}{ Group I } & \multicolumn{2}{c|}{ Group II } & \multirow{2}{*}{ Test value* } & \multirow{2}{*}{ P-value } & \multirow{2}{*}{ Sig. } \\
\cline { 2 - 6 } & No. & \% & No. & \% & & & \\
Left & 15 & $75.0 \%$ & 18 & $90.0 \%$ & & \\
Right & 0 & $0.0 \%$ & 0 & $0.0 \%$ & 1.558 & 0.459 & NS \\
Bilateral & 5 & $25.0 \%$ & 2 & $10.0 \%$ & & & \\
\hline
\end{tabular}

P-value >0.05: Non significant (NS); P-value <0.05: Significant (S); P-value< 0.01: highly significant (HS)

$*$ :Chi-square test

The previous table shows that the left side is dominant and there was no statistically significant difference found between group I and group II regarding affected side of the studied cases with p-value $=0.459$.

Table (3): Comparison between group I and group II regarding complaint.

\begin{tabular}{|l|c|c|c|c|c|c|c|}
\hline \multirow{2}{*}{ Complaint } & \multicolumn{2}{|c|}{ Group I } & \multicolumn{2}{c|}{ Group II } & \multirow{2}{*}{ Test value* } & \multirow{2}{*}{ P-value } & \multirow{2}{*}{ Sig. } \\
\cline { 2 - 5 } & No. & \% & No. & \% & & & \\
Swelling \& Pain & 8 & $40.0 \%$ & 7 & $35.0 \%$ & & & \\
Pain & 5 & $25.0 \%$ & 4 & $20.0 \%$ & 0.432 & 0.933 & NS \\
Heavy & 4 & $20.0 \%$ & 5 & $25.0 \%$ & & & \\
Swelling & 3 & $15.0 \%$ & 4 & $20.0 \%$ & & & \\
\hline
\end{tabular}

P-value >0.05: Non significant (NS); P-value <0.05: Significant (S); P-value< 0.01: highly significant (HS)

*:Chi-square test

The previous table shows that the most complain is swelling and pain and show that there was no statistically significant difference found between group I and group II regarding complaint of the studied cases with $\mathrm{p}$-value $=$ 0.933

Table (4): Comparison between group I and group II regarding past history.

\begin{tabular}{|l|c|c|c|c|c|c|c|}
\hline \multirow{2}{*}{ Past history } & \multicolumn{2}{|c|}{ Group I } & \multicolumn{2}{c|}{ Group II } & \multirow{2}{*}{ Test value* } & \multirow{2}{*}{ P-value } & \multirow{2}{*}{ Sig. } \\
\cline { 2 - 8 } & No. & \% & No. & \% & & & \\
Pts with no history & 12 & $60.0 \%$ & 9 & $45.0 \%$ & & & \\
Appendectomy & 2 & $10.0 \%$ & 3 & $15.0 \%$ & & \\
Cholecystitis & 1 & $5.0 \%$ & 2 & $10.0 \%$ & \multirow{2}{*}{3.629} & 0.604 & NS \\
Umbilical hernia & 1 & $5.0 \%$ & 3 & $15.0 \%$ & & & \\
Splenectomy & 0 & $0.0 \%$ & 1 & $5.0 \%$ & & & \\
Hemorrhoidectomy & 4 & $20.0 \%$ & 2 & $10.0 \%$ & & & \\
\hline
\end{tabular}

P-value >0.05: Non significant (NS); P-value <0.05: Significant (S); P-value $<0.01$ : highly significant (HS)

$*$ :Chi-square test

The previous table shows that most of patients had no previous operation and show that there was no statistically significant difference found between group I and group II regarding past history of the studied cases with $\mathrm{p}$-value $=0.604$.

Table (5): Comparison between group I and group II regarding operative time.

\begin{tabular}{|l|c|c|c|c|c|c|c|}
\hline \multirow{2}{*}{ Operative time } & \multicolumn{2}{|c|}{ Group I } & \multicolumn{2}{c|}{ Group II } & \multirow{2}{*}{ Test value* } & \multirow{2}{*}{ P-value } & \multirow{2}{*}{ Sig. } \\
\cline { 2 - 8 } & No. & \% & No. & \% & & & \\
$20-20$ & 8 & $40.0 \%$ & 10 & $50.0 \%$ & & \multirow{2}{*}{0.599} & NS \\
$25-25$ & 8 & $40.0 \%$ & 5 & $25.0 \%$ & 1.026 & & \\
\hline
\end{tabular}

P-value >0.05: Non significant (NS); P-value <0.05: Significant (S); P-value< 0.01: highly significant (HS)

*:Chi-square test

The previous table shows that the mean operative time was 24.20 minutes in group I and 23.85 minutes in group II and there was no statistically significant difference between both groups as regard the operative time, since with pvalue $=0.599$. 
Table (6): Comparison between group I and group II regarding hospital stay.

\begin{tabular}{|l|c|c|c|c|c|c|c|}
\hline \multirow{2}{*}{ Hospital stay } & \multicolumn{2}{|c|}{ Group I } & \multicolumn{2}{c|}{ Group II } & \multirow{2}{*}{ Test value* } & \multirow{2}{*}{ P-value } & \multirow{2}{*}{ Sig. } \\
\cline { 2 - 7 } & No. & $\%$ & No. & \% & & & \\
1-2 day & 16 & $80.0 \%$ & 18 & $90.0 \%$ & & \multirow{2}{*}{ NS } \\
3-4 day & 3 & $15.0 \%$ & 2 & $10.0 \%$ & 1.318 & 0.517 & \\
5-6 day & 1 & $5.0 \%$ & 0 & $0.0 \%$ & & & \\
\hline
\end{tabular}

P-value >0.05: Non significant (NS); P-value <0.05: Significant (S); P-value < 0.01: highly significant (HS)

*:Chi-square test

The previous table shows that the mean hospital stay was 2.10 days in group I and 2.20 days in group II and there was no statistically significant difference between both groups as regard the hospital stay, since p-value $=0.517$.

Table (7): Comparison between group I and group II regarding postoperative scrotal ultrasound.

\begin{tabular}{|c|c|c|c|c|c|c|c|}
\hline \multirow{2}{*}{$\begin{array}{l}\text { Post-operative } \\
\text { scrotal ultrasound }\end{array}$} & \multicolumn{2}{|c|}{ Group I } & \multicolumn{2}{|c|}{ Group II } & \multirow{2}{*}{ Test value* } & \multirow{2}{*}{ P-value } & \multirow{2}{*}{ Sig. } \\
\hline & No. & $\%$ & No. & $\%$ & & & \\
\hline No collection & 15 & $75.0 \%$ & 15 & $75.0 \%$ & & & \\
\hline Minimal collection & 5 & $25.0 \%$ & 5 & $25.0 \%$ & 0.000 & 1.000 & NS \\
\hline Mild collection & 0 & $0.0 \%$ & 0 & $0.0 \%$ & & & \\
\hline
\end{tabular}

P-value >0.05: Non significant (NS); P-value <0.05: Significant (S); P-value < 0.01: highly significant (HS)

$*$ :Chi-square test

The previous table shows that most of patients had no collection and show there was no statistically significant difference found between group I and group II regarding return to postoperative scrotal ultrasound among the studied cases with p-value $=1.000$.

Table (8): Comparison between group I and group II regarding adherence of tests to scrotal wall.

\begin{tabular}{|l|c|c|c|c|c|c|c|}
\hline \multicolumn{1}{|c|}{$\begin{array}{c}\text { Adherence of tests } \\
\text { to scrotal wall }\end{array}$} & \multicolumn{2}{|c|}{ Group I } & \multicolumn{2}{c|}{ Group II } & \multirow{2}{*}{ Test value* } & \multirow{2}{*}{ P-value } & \multirow{2}{*}{ Sig. } \\
\cline { 2 - 8 } & No. & $\mathbf{\%}$ & No. & \% & & & \\
\hline No adherence & 19 & $95.0 \%$ & 20 & $100.0 \%$ & 1.026 & 0.311 & NS \\
Adherence & 1 & $5.0 \%$ & 0 & $0.0 \%$ & & \\
\hline
\end{tabular}

P-value >0.05: Non significant (NS); P-value <0.05: Significant (S); P-value< 0.01: highly significant (HS)

$*$ :Chi-square test

The previous table shows that most of cases had no adherence by follow up and show there was no statistically significant difference found between group I and group II regarding adherence of tests to scrotal wall among the studied cases with p-value $=0.311$.

Table (9): Comparison between group I and group II regarding postoperative hydrocele.

\begin{tabular}{|c|c|c|c|c|c|c|c|}
\hline \multirow{2}{*}{$\begin{array}{l}\text { Post-operative } \\
\text { hydrocele }\end{array}$} & \multicolumn{2}{|c|}{ Group I } & \multicolumn{2}{|c|}{ Group II } & \multirow{2}{*}{ Test value* } & \multirow{2}{*}{ P-value } & \multirow{2}{*}{ Sig. } \\
\hline & No. & $\%$ & No. & $\%$ & & & \\
\hline $\begin{array}{l}\text { Positive } \\
\text { Negative }\end{array}$ & $\begin{array}{c}0 \\
20\end{array}$ & $\begin{array}{c}0.0 \% \\
100.0 \%\end{array}$ & $\begin{array}{c}0 \\
20\end{array}$ & $\begin{array}{c}0.0 \% \\
100.0 \%\end{array}$ & NA & NA & NA \\
\hline
\end{tabular}

P-value >0.05: Non significant (NS); P-value <0.05: Significant (S); P-value < 0.01: highly significant (HS)

$*$ :Chi-square test

The previous table shows that there was no incidence of postoperative hydrocele found in the two studied groups. Both are negative by $100 \%$, so no comparison were done between the two groups regarding postoperative hydrocele .

\section{DISCUSSION}

Varicocelectomy is the second most common cause of scrotal hydrocele ${ }^{(8)}$.

It is thought that hydrocele is caused by damage of lymphatic vessels that drains the testicle during operation ${ }^{(9)}$.

Formation of hydrocele after varicocelectomy is extremely variable ranging from $0 \%$ to $25 \%$ of operated patients, depending on surgical technique ${ }^{(10)}$.

Varicocele may lead to increased intrascrotal temperature that interfere testicular function and tense hydroceles might also cause a pressure atrophy of the testis ${ }^{(11)}$.
The technique used for varicocelectomy can affect the hydrocele rate. Approaches that avoid dissection of the spermatic cord, such as sclerotherapy of the internal spermatic veins, are associated decreased risks of hydrocele formation ${ }^{(12)}$.

Many technical modifications can be used to avoid damage to the lymphatic vessels during spermatic cord dissection ${ }^{(13)}$.

microscope is generally accepted to be a key component of a lymphatic-sparing varicocelectomy. So, microsurgical low inguinal varicocelectomy is 
associated with a very low hydrocele rate, reaching $0 \%$ (14).

Microscpe has an advantage for varicocelectomy performed using minimally-invasive surgery ${ }^{(15)}$.

Lymphatic enhancement with vital dye has been used as an additional means to prevent post-operative hydrocele ${ }^{(16)}$.

Techniques that spare internal spermatic artery such as high ligation of the internal spermatic vessels (Palomo procedure) might also use for lowering the rate of hydrocele formation ${ }^{(17)}$.

Eversion of tunica vaginalis has been suggested to reduce the risk of hydrocele formation in patients who undergo varicocelectomy without the aid of microsurgery ${ }^{(18)}$.

In this study eversion of tunica vaginalis proved to be effective in avoidance of hydrocele formation after varicocelectomy as there is no case developed hydrocele during the follow up period and as effective as microsurgical varicocelectomy.

This result came in accordance to Castagnetti $\boldsymbol{e t}$ al. who compared 96 cases of subinguinal varicocelectomy plus eversion of tunica vaginalis with 46 patients who underwent subinguinal varicocelectomy alone $^{(19)}$.

So, tunica vaginalis excision and eversion might be more effective than excision alone. In another study by Tsikopoulos et al. who compared 15 patients who underwent the Palomo procedure with excision of the tunica vaginalis with patients who underwent the Palomo procedure without eversion of tunica ${ }^{(20)}$.

We also reported no significant differences in complications rate between varicocelectomy with eversion of tunica vaginalis and varicocelectomy without eversion of tunica vaginalis. Improvement in sperm count, motility and morphology occurred in both groups. Hence, the pregnancy rates after varicocelectomy increased because of the increased quantity and quality of sperm in both groups without any significant difference. This came in accordance to Jungwirth, et al. and Chu et al. results ${ }^{(21)}$.

In our study, the highest age group of the patients was between 31 and 40 years [age range of all groups was 17-52 years]. All the patients had longstanding varicocele, with the time from patient's discovery of the illness to presentation ranging from 6 months to 2 years. In the present study results we found that there was no significant statistical difference between groups I and II as regarding age.

The mean age of involved patient's age group in group I and in group II was 30.75 \pm 10.67 and $29.35 \pm 8.93$ years respectively. This will exclude any age related healing differences in our research comparison.

As regard patients' complaint in our groups, Most of patient's complaint was swelling in both groups and few cases were complaining of swelling and heaviness or swelling and pain. And there was no statistically significant difference between both groups as regard the patient's complaint, since $\mathrm{T}$ value 0.05 (0.432) \&P-value (.933)

According to side of varicocele, most of varicocele were in the left side in both groups as 15 cases in group I and 18 cases in group II. And there was no statistically significant difference between both groups as regard the side of hydrocele, since $\mathrm{T}$ value 0.05 (1.558) \& P-value (0.459).

The most common past history of operation in our patients was hemorrhoidectomy in group I and appendectomy in group II, while the least reported past history of operation was splenectomy and in both groups. And there was no statistically significant difference between both groups as regard the Past history of operations, since $\mathrm{T}$ value 0.05 (3.629).\& Pvalue (0.604).

The operation time was insignificantly different between both groups. However, the difference in operation time within each group was only found in the bilateral varicocele cases as it takes more time during operation in comparison with the unilateral varicocele cases. Since T-value 0.05 (1.026) \& P-value (0.599).

Regarding return to daily work there was no statistically significant difference between both groups as regard the return to daily work, since $\mathrm{T}$ value 0.05 (0.625) \& P-value (0.732).

In our study, regarding to hospital stay there was no statistically significant difference between both groups as regard the hospital stay, since $\mathrm{T}$ value 0.05 (1.318) \& P-value (0.517). The hospital stay of patients post operatively ranged from 1-6 days in both groups with most of patients discharged after 1-2 days in both groups.

Post-operative ultrasound in our patients showed most of patients in both groups had no collection by scrotal ultrasound post operatively, there was minimal to mild collection in 1-5 patients in each group confined to cases with redundant tunica and partial excision of tunica was done by electrocautery before eversion, and there was no statistically significant difference between both groups as regard the results of postoperative ultrasound in our patients, since $\mathrm{T}$ value 0.05 (0.00)\& P-value (1.00)

Regarding to suture removal in our study there was no statistically significant difference between both groups as regard the suture removal, since $\mathrm{T}$ value 0.05 (0.362)\& P-value (0.834). Suture removal period ranged from 8 days to more than 12 days with most of patients had their suture removed from 8-9 days in both groups. Except in cases associated with partial dehiscence or discharge from wound, sutures were removed between 12-14 days and the patients were hospitalized and observed till the wound healed.

According to scrotal edema in post-operative follow up, 18 patients in group I had no scrotal edema and only two cases had scrotal edema. In group II 19 cases had no scrotal edema post operatively and only one case had scrotal edema in group II and were treated by anti-edematous measures and scrotal support. Scrotal 
edema was prominent in cases associated with excision of the tunica vaginalis. And there was no statistically significant difference between both groups as regard the scrotal edema, since $\mathrm{T}$ value $0.05(0.360) \& \mathrm{P}$ - value (0.549).

Most of patients in both groups in our study showed no adherence of testes to scrotal wall, in follow up, only (1) cases in group I and there no any case in group II showed adherence of testes to scrotal wall. And there was no statistically significant difference between both groups as regard the adherence of testes to scrotal wall, since $\mathrm{T}$ value $0.05(0.1 .026) \&$ $\mathrm{P}$ - value (0.311).

In our study, as a comparison between the two groups there was any hydrocele in both groups

In our study the drain was removed in group I in range from 2-3 days with most of patients (15) had drain removed after 2 days, (3) after 3 days and (4) patients after 4 days. Drain was removed when the amount of fluid from it was less than $25 \mathrm{ml}$. Drain sites infection occurred in 6 cases in group I, and was treated by proper antibiotics and dressing. The mean time of drain removal in group I was 2.55 days with minimum after 2 days and maximum after 3 days.

The Amount of fluid from drain in our study in group I ranged from $5 \mathrm{ml}-30 \mathrm{ml}$ with most of patients (10) represented $50 \%$ drained $5 \mathrm{ml}$ and (1) patient represented $5 \%$ drained $30 \mathrm{ml}$. The mean amount of fluid from drain in group I was $11.75 \mathrm{ml}$ with minimum $5 \mathrm{ml}$ and maximum $30 \mathrm{ml}$.

The mean follow up of patients in our study was 6.40 weeks in group I and 5.10 weeks in group II which was at 2 weeks, 1 month, 2 months, 3 months with no recurrence found and there was no statistically significant difference between both groups as regard the follow up, since T value 0.05 (1.254).

\section{CONCLUSION}

It could be concluded that for reduction of the incidence of hydrocele after varicocelectomy, eversion of tunica vaginalis can be afforded as adjunctive in operation theatre performing sub inguinal varicocelectomy without the aid of an operating microscope.

\section{REFERENCES}

1. Hargreave TB (1993): Varicocele: A clinical enigma. $\mathrm{Br} \mathrm{J}$ Urol., 72:401-8.

2. Barwell R (1985): One hundred cases of varicocele treated by subcutaneous wire loop. Lancet , 1:978.

3. Dubin L, Amelar R (1977): Varicocelectomy 986 cases in a 12 year study. Urology, 10:446-9.
4. Kogan SJ, Hulbert WC, Cockett AT(1984):Pediatric varicoceles; changing concepts. In: Ehrlich RE, editor. Dialogue in Pediatric Urology. Vol. 7. Pearl River (New York): William Miller.

5. Kass EJ, Belman AB (1987): Reversal of testicular growth failure by varicocele ligation. J Urol., 137:475-6.

6. Miyaoka R, Esteves SC (2012): A critical appraisal on the role of varicocele in male infertility. Adv Urol., 2012:597495.

7. Sathya Srini V, Belur Veerachari S (2011): Does varicocelectomy improve gonadal function in men with hypogonadism and infertility? Analysis of a prospective study. Int J Endocrinol., 2011:916380.

8. Cho SY, Kim TB, Ku JH, Paick JS, Kim SW (2011): Beneficial effects of microsurgical varicocelectomy on semen parameters in patients who underwent surgery for causes other than infertility. Urol., 77:1107-10.

9. Diegidio P, Jhaveri JK, Ghannam S, Pinkhasov R, Shabsigh R, Fisch H (2011): Review of current varicocelectomy techniques and their outcomes. BJU International,108 (7):115772.

10. Alaa HA (2018): Laparoscopic versus open varicocelectomy comparative study for early post-operative complications among patients in Basrah, Iraq. Int Surg J., 5(4):1176

11. Shamsa A, Nademi M, Aqaee M, Fard AN, Molaei $M$ (2010): Complications and the effect of varicocelectomy on semen analysis, fertility, early ejaculation and spontaneous abortion. Saudi J Kidney Dis Transpl., 21:1100-5.

12. Mattews GJ, Matthews ED, Goldstein M (2014): Induction of spermatogenesis and achievement of pregnancy after microsurgical varicocelectomy in men with azoospermia and severe oligoasthenosperm. Fertil Steril., 70 (1):71-5.

13. Cayan S, Acar D, Ulger S, Akbay E (2005): Adolescent varicocele repair: long-term results and comparison of surgical techniques according to optical magnification use in 100 cases at a single university hospital. J. Urol., 174:2003-6.

14. Yaman O, Soygur T, Zumrutbas AE, Resorlu B (2006): Results of microsurgical subinguinal varicocelectomy in children and adolescents. Urol., 68:410-2.

15. Singh DR, Gupta SK, Gupta $S$ (1996): Lord's procedure: a curative outpatient operation for primary hydrocele. J. Indian Med. Assoc., 94:141-2.

16. Rodriguez WC, Rodriguez DD, Fortuno RF (1981): The operative treatment of hydrocele: a comparison of 4 basic techniques. J Urol., 125;804-5.

17. Van der Brink BA, Palmer LS, Gitlin J, Levitt SB, Franco I (2007): Lymphatic-sparing laparoscopic varicocelectomy versus microscopic varicocelectomy: is there a difference? Urol., 70:1207-10.

18. Glassberg KI, Poon SA, Gjertson C K, DeCastro GJ, Misseri $R$ (2008): Laparoscopic lymphatic sparing varicocelectomy in adolescents. J Urol., 180:326-30.

19. Castagnetti M, Cimador $M$, DiPace MR, Catalano $P$, DeGrazia E (2008): 'Preemptive hydrocelectomy' in subinguinal varicocelectomy. Urol Int., 81(1):14-6.

20. Kroese NM, de Lange JA, Collins JL (2013): Evers Varicocele surgery, new evidence.Human Reproduction Update, 19 (4):31.

21. Chu DI (2017): The natural history of semen parameters in untreated asymptomatic adolescent varicocele patients: a retrospective cohort study. J Pediatr. Urol., 13:77.e1-5. 